\title{
How does driving license withdrawal affect subjective well-being? A Swedish comparative survey study of visual field loss
}

\author{
Jonna Nyberg ${ }^{1,3^{*}} \mathbb{0}$, Gunilla Björklund ${ }^{1}$, Åsa Aretun ${ }^{1}$, Hans-Yngve Berg ${ }^{4,5}$ and Thomas Strandberg 23,6
}

\begin{abstract}
Research has found strong relationships between access to transport, accessibility of activities, and subjective well-being (SWB), and society is said to be car dependent. Accordingly, this study investigates, in a Swedish context, whether and how withdrawal of a driving license for a private car due to visual field loss (VFL) affects SWB. A web survey was used for statistical comparisons of three respondent groups $(n=436)$ : people with a driving license, people with a driving license and VFL, and people whose driving license was withdrawn due to VFL. The inclusion criterion for all participants was that they should have a diagnosis that could cause VFL. The no-license group had lower overall SWB than did respondents with driving licenses. The no-license group also perceived less access to transport means in order to live a life to be satisfied with than did the other groups. The most used transport means in the no-license group was getting a lift in a car, though this group had a strong desire to drive a car. Few respondents in the license groups wanted to use specific transport means to a greater extent, car driving being the most used transport means. Some inter-group differences were seen regarding how access to activities (measured by frequency of actual trips) affected SWB. This study found a significant negative effect of driving license withdrawal on SWB. However, the results imply that qualitative aspects other than the relationship between the frequencies of trips and activities might also affect SWB, and more research on this subject is needed.
\end{abstract}

Keywords: Accessibility, Transport disadvantage, Car dependence, Impairment, License cessation, Mobility

\section{Introduction}

In Sweden, 8000-9000 driving licenses are withdrawn yearly for medical reasons [34], including due to visual field loss (VFL), and these withdrawals can affect individuals' subjective well-being (SWB). Common reasons for VFL are glaucoma, diabetes, and stroke [27]. Globally, about 600,000 people suffer a stroke or other brain injury every year [23]. In 2019, an estimated 463 million people in the world aged 20-79 years had diabetes [15], and in 2014, it was estimated that 76 million people aged $40-80$ years would have glaucoma by 2020 [33]. These

\footnotetext{
${ }^{*}$ Correspondence: jonna.nyberg@vti.se

1 Swedish National Road and Transport Research Institute, Linköping, Sweden

Full list of author information is available at the end of the article
}

diagnoses can affect people of all ages but are most common among the elderly (cf. [38]). Furthermore, since the population is ageing in many countries, these diagnoses are expected to increase in the future [21, 26, 33]. This suggests that driving license withdrawal due to VFL will increase in the population as well, which might affect SWB.

Studies have shown that there is a relationship between individuals' access to car transport and social exclusion [18]. In the western world, high dependence on private car use can generally be explained by long distances from home to everyday activities, with access being provided by extensive road networks adapted for private car travel and access via other modes being limited for many people [11]. Extensive research examines elderly people and the consequences of driving license 
withdrawal, such as social exclusion (e.g., [7, 39]), depression (e.g., [20]), and reduced independence (e.g., [1]). Similar results have been found in studies of people with impairments and license withdrawal (e.g., [24, 29, 35]).

Related to the above description, this study is based on the assumption that access to transport facilitates the accessibility of needed and desired activities in everyday life: activities that influence SWB [19]. The accessibility concept has been defined in many ways [2], being measured in different ways for different purposes (see, e.g., [13]). Here, we understand accessibility from an individual perspective, taking into account individuals' own perceptions and characteristics (cf. [28]). The definition of SWB varies, and researchers have used the terms SWB, life satisfaction, and happiness synonymously [19]. SWB is often described as consisting of two specific aspects, distinguishing between life evaluation (i.e., cognitive evaluation of the respondent's life as a whole, or of aspects of it) and affects (experienced by the respondent at particular times) [25].

Research on accessibility is comprehensive [36], as well as research on transport and social disadvantage, and have long been studied [17]. In comparison, research on the links between transport, accessibility, and SWB has been growing for only about a decade [19] (for reviews of the use of SWB in transport research, see [8-10, 22, 30]). Nevertheless, De Vos et al. [10] has called for research with other focus than the well-researched group of elderly people, while Van Wee [36] has emphasized that attention should be paid to the importance of the context and not, as is customary, to the case or area (e.g., city, region, or country). Furthermore, Makarewicz and Németh [16] stated that even though several studies have considered how access to and participation in daily activities can affect SWB, "we know very little about the impact of transportation accessibility on what researchers call subjective wellbeing (SWB)" (p. 179). A previous interview study found that driving license withdrawal due to VFL can lead to transport-related consequences such as limited or no opportunities for participation in out-of-home activities and feelings of dependence, irrespective of sociodemographic characteristics (e.g., age and residence) [24]. Still, we need complementary research into the extent of the problem in this target group, regardless of sociodemographic characteristics.

The aim is to investigate, in a Swedish context and a heterogeneous-age group, how the withdrawal of driving license for a private car due to VFL affects SWB. Assuming that access to transport facilitates the accessibility of activities that generate SWB, the research questions are:
1. Are there differences in SWB between a group of people whose driving license was withdrawn due to VFL and groups with a driving license?

2. What differences are seen between the groups regarding accessibility?

The aspects of SWB are referred to as SWB dimension of life satisfaction and SWB dimension of affects. Accessibility is measured by Frequency of trips for participation in different activities, Use of transport means to reach different activities, and Perceived access to transport means in order to live a life to be satisfied with.

\section{Material and methods}

\subsection{Procedure and participants}

A stratified random selection of people whose driving license was withdrawn due to VFL could not be made because of confidentiality legislation. Participants were instead recruited via the websites of the Swedish Diabetes Association, Swedish Glaucoma Association, and Swedish Stroke Association, as well as via the magazines of the Swedish Stroke Association and Swedish Glaucoma Association. Further recruitment was done via the Swedish National Road and Transport Research Institute (VTI), which provided contact information on about 900 people with VFL; these people received an emailed invitation. Also, the project was advertised on the VTI website for recruiting purposes.

The reference group, i.e., people with a driving license, was divided into one group with VFL and another without VFL. Hence, the inclusion criterion for all participants was that they should have a diagnosis that could cause VFL. Groups included were:

1. License group $(n=80)$. Those who completed the questionnaire intended for people with a driving license and who declared either "I have no VFL according to examinations conducted by ophthalmologists" or "I have not been to an ophthalmologist to check whether I have VFL".

2. License-VFL group $(n=91)$. Those who completed the questionnaire intended for people with a driving license and who declared "I have VFL and have a driving license through an exemption from the medical driving license requirements of the Swedish Transport Agency", "I have VFL and have therefore received a limited driving license", or, in the "Other" option, wrote that they have minor VFL that does not affect their driving.

3. No-license group $(n=265)$. Those who completed the questionnaire intended for people whose driving license was withdrawn due to VFL. 
In total, 436 participants were included in the study. Of the 581 who registered for the web survey, 58 answered only the background questions, or parts of them, and 78 discontinued the questionnaire at the halfway point, so their results were excluded. Nine people who responded either "Do not know" or "Do not want to answer" regarding any of the dependent variables or who answered "Other" to the question about family situation were also excluded. The data collection was conducted between November 2018 and February 2019. The study was approved by the Regional Ethics Board of Linköping (No. 2018/354-31).

\subsection{Questionnaires}

The questionnaires comprised three sections. Section one covered background data (i.e., gender, age, and accommodation) and, for those whose license had been withdrawn, year of withdrawal. Section two covered the frequency of trips to different activities and the transport means used on these trips. The respondents were asked whether they were satisfied with the transport means used, and whether they would prefer to use specific transport means to a greater extent. For those with a driving license, further questions were added concerning VFL and their driving license. The respondents were also asked if they had any impairment other than VFL that might affect their opportunities to use any of the described transport means. Section three contained standardized items from the Swedish version of the special topic module of the EU-SILC survey [31] addressing the two dimensions of SWB mentioned above [12]. The questionnaires were pretested, after which some minor revisions were made.

\subsection{Variables included in the analyses}

To measure the $S W B$ dimension of life satisfaction, the following question was used: "Overall, how satisfied are you with your life nowadays?", to be answered using an 11 -point response scale $(0=$ not at all satisfied, $10=$ completely satisfied). Respondents who answered "Don't know" or "Do not want to answer" were excluded from the analysis. The questionnaires included several items about life satisfaction measuring current life, financial situation, current work, leisure time, and personal relationships with family, friends, neighbours, and other acquaintances. However, it was decided to use only the item measuring overall life satisfaction, mainly because of the large dropout for the job satisfaction item but also because this item could be seen as measuring overall life satisfaction.

To measure the SWB dimension of affects, an index (Cronbach's alpha $=0.89$ ) was created using questions about negative and positive emotions: "How much of the time over the past four weeks have you felt (very nervous, down in the dumps, calm and peaceful, downhearted and depressed, happy, lonely)?", to be answered using a five-point response scale $(1=$ all of the time, $5=$ none of the time). The mean value of all answers constituted the index for each respondent. Questions about positive emotions were reversed to create a uniform scale. If respondents answered "Don't know" or "Do not want to answer" to one or two of the six questions, these answers were replaced with the mean value of the other valid answers for that respondent. Imputing with the mean is a common way to deal with missing values, and here we assumed that the participants would probably have not answered these questions if we had not provided the response options. Such imputation was done for 13 of the participants. If a respondent failed to answer three or more questions, however, the entire index was set to "missing".

Questions concerning Frequency of trips for participation in different activities (i.e., trips to work/studies, leisure activities, friends and relatives, care centre/hospital/ pharmacy, shopping/other errands) had the answer alternatives: "Yes, 4 times/week or more", "Yes, 2-3 times/ week", "Yes, 2-4 times/month", "Yes, once a month or less often", "No, never", and "Don't know".

Use of transport means to reach different activitiesan approximate variable capturing access to transport means-was measured by asking "Out of ten occasions, how many times do you travel by the following transport means (drive a car, get lift in a car, public transport, special transport service, walk, bicycle, moped/motorcycle) to (work/studies, leisure activities, friends and relatives, care centre/hospital/pharmacy, shopping/other errands)?".

Perceived access to transport means in order to live a life to be satisfied with was measured by the question: "Do you have sufficient access to transport means in order to live a life to be satisfied with?" Answers were given using an 11-point scale ranging from $0=n o t$ at all to $10=$ completely. Connected to this question was the item Desire for greater use of a transport means, related to the statement: "To live a life that I am satisfied with, I would to a greater extent (drive a car, get a lift in a car, use public transport, use special transport service, walk, use a bicycle, use a moped/mc)".

The following were included in the analyses as control variables: affiliation group, gender, age, residence, employment, highest education, accommodation, family situation, number of cars in household, driving baseline, and diagnosis, with an additional question for the no-license group about the year of driving license withdrawal. The response scales for these variables are presented in Table 1. 
Table 1 Characteristics of the three respondent groups; percentages within parentheses

\begin{tabular}{|c|c|c|c|c|c|c|c|}
\hline Variables & Categories & License & License-VFL & No-license & Total & $p$ value & $x^{2}$ \\
\hline \multirow[t]{3}{*}{ Gender } & Female & $42(52.5)$ & $19(20.9)$ & $44(16.6)$ & $105(24.1)$ & 0.000 & $43.95^{* * *}$ \\
\hline & Male & $38(47.5)$ & $72(79.1)$ & $221(83.4)$ & $331(75.9)$ & & \\
\hline & Total & $80(100.0)$ & $91(100.0)$ & $265(100.0)$ & $436(100.0)$ & & \\
\hline \multirow[t]{4}{*}{ Number in age group } & 20-49 years & $41(51.3)$ & $11(12.1)$ & $33(12.5)$ & 85 (19.5) & 0.000 & $70.83^{* * *}$ \\
\hline & 50-69 years & $32(40.0)$ & $55(60.4)$ & $134(50.6)$ & $221(50.7)$ & & \\
\hline & 70-95 years & $7(8.8)$ & $25(27.5)$ & $98(37.0)$ & $130(29.8)$ & & \\
\hline & Total & $80(100.0)$ & $91(100.0)$ & 265 (100.0) & $436(100.0)$ & & \\
\hline \multirow[t]{5}{*}{ Residence } & City $>50,000$ & $39(48.8)$ & $32(35.2)$ & $93(35.1)$ & 164 (37.6) & 0.227 & 8.15 \\
\hline & City $10,000-50,000$ & $21(26.3)$ & $22(24.2)$ & $68(25.7)$ & $111(25.5)$ & & \\
\hline & Town 200-9999 & $9(11.3)$ & $17(18.7)$ & $39(14.7)$ & 65 (14.9) & & \\
\hline & Countryside/rural & $11(13.8)$ & $20(22.0)$ & $65(24.5)$ & $96(22.0)$ & & \\
\hline & Total & $80(100.0)$ & $91(100.0)$ & $265(100.0)$ & $436(100.0)$ & & \\
\hline \multirow[t]{3}{*}{ Employment } & Worker/student & $56(70.0)$ & $43(47.3)$ & $93(35.1)$ & $192(44.0)$ & 0.000 & $30.86^{* * *}$ \\
\hline & Unemployed/long-term sick/retired/other ${ }^{b}$ & $24(30.0)$ & $48(52.8)$ & $172(64.9)$ & $244(56.0)$ & & \\
\hline & Total & $80(100.0)$ & $91(100.0)$ & $265(100.0)$ & $436(100.0)$ & & \\
\hline \multirow[t]{5}{*}{ Highest educationa } & Lower secondary school (age 7-15) & $2(2.5)$ & $7(7.7)$ & $30(11.3)$ & $39(8.9)$ & 0.066 & 11.83 \\
\hline & Upper secondary school (age 16-18) & $18(22.5)$ & $25(27.5)$ & $78(29.4)$ & $121(27.8)$ & & \\
\hline & Further education (other than university) & $18(22.5)$ & $21(23.1)$ & $65(24.5)$ & $104(23.9)$ & & \\
\hline & Higher education (e.g., university) & $42(52.5)$ & $38(41.8)$ & $92(34.7)$ & $172(39.5)$ & & \\
\hline & Total & $80(100.0)$ & $91(100.0)$ & $265(100.0)$ & $436(100.0)$ & & \\
\hline \multirow[t]{3}{*}{ Accommodation } & Apartment & $33(41.3)$ & $24(26.4)$ & $88(33.2)$ & $145(33.3)$ & 0.120 & 4.25 \\
\hline & Detached or terraced house/other ${ }^{\mathrm{b}}$ & $47(58.8)$ & 67 (73.6) & $177(66.8)$ & $291(66.7)$ & & \\
\hline & Total & $80(100.0)$ & $91(100.0)$ & $265(100.0)$ & $436(100.0)$ & & \\
\hline \multirow[t]{5}{*}{ Family situation ${ }^{c}$} & Single without children & $19(23.8)$ & $15(16.5)$ & $54(20.4)$ & $88(20.2)$ & 0.456 & 5.71 \\
\hline & Single with children & $3(3.8)$ & $2(2.2)$ & $15(5.7)$ & $20(4.6)$ & & \\
\hline & Cohabiting without children & $33(41.3)$ & $48(52.8)$ & $132(49.8)$ & $213(48.9)$ & & \\
\hline & Cohabiting with children & $25(31.3)$ & $26(28.6)$ & $64(24.2)$ & $115(26.4)$ & & \\
\hline & Total & $80(100.0)$ & $91(100.0)$ & $265(100.0)$ & $436(100.0)$ & & \\
\hline \multirow[t]{4}{*}{ Number of cars in household } & No car & $8(10.1)$ & $4(4.4)$ & $35(13.2)$ & $47(10.8)$ & 0.021 & $11.60^{*}$ \\
\hline & One car & $37(46.8)$ & $38(41.8)$ & $135(50.9)$ & $210(48.3)$ & & \\
\hline & More than one car & $34(43.0)$ & $49(53.9)$ & 95 (35.9) & $178(40.9)$ & & \\
\hline & Total & $79(100.0)$ & $91(100.0)$ & $265(100.0)$ & $435(100.0)$ & & \\
\hline \multirow[t]{4}{*}{ Diagnosis } & Stroke (only) & $13(16.3)$ & $33(36.3)$ & $105(39.6)$ & $151(34.6)$ & 0.000 & $127.82^{* * *}$ \\
\hline & Diabetes (only) & $56(70.0)$ & $8(8.8)$ & $35(13.2)$ & $99(22.7)$ & & \\
\hline & Glaucoma (only) & $7(8.8)$ & $35(38.5)$ & $94(35.5)$ & $136(31.2)$ & & \\
\hline & Combined and/or other diagnosis & $4(5.0)$ & $15(16.5)$ & $31(11.7)$ & $50(11.5)$ & & \\
\hline
\end{tabular}

${ }^{*} p<.05 ;{ }^{* *} p<.01 ;{ }^{* * *} p<.001$

${ }^{\text {a }}$ The categories are translated from Swedish to be consistent with the terms used in British English

${ }^{\mathrm{b}}$ Merged categories

"The "Other" category was initially included in the Family situation variable. As this category is difficult to interpret and only seven people selected this category, it was removed and not included in the analysis

To avoid the mass significance problem when needed, the tests were adjusted using Bonferroni correction.

\subsection{Statistical analyses}

Chi-square tests were conducted to compare nominal variables across the respondent groups. As we consider the responses regarding the two following dependent variables as reflecting an underlying continuous scale (see, e.g., [32]), differences across the three respondent groups in level of overall SWB (comprising the SWB dimension of life satisfaction and SWB dimension of affects) were tested using multiple linear regression analyses, with control variables added. For the same reason, the same procedure was undertaken for the dependent variable Perceived access to transport means in order to live a life to be satisfied with. Pearson correlation coefficients were 
calculated between the variable Years of driving license withdrawal and the two SWB dimensions. The nonparametric Kruskal-Wallis (H) test and Mann-Whitney $\mathrm{U}$ test were used to compare the groups' frequencies of trips for participation in different activities. Non-parametric tests were used here because the response scale consisted of ordered categories. These analyses were performed using SPSS version 24.

\subsection{Characteristics of respondents}

Descriptive statistics and Chi-square tests regarding the characteristics of the three respondent groups are presented in Table 1. No differences were found across the groups regarding residence, highest education, accommodation, and family situation. Significant differences were seen between the three groups regarding gender, age, employment, number of cars in household, and diagnosis. The license group contained more women than men, while the other two groups comprised mostly men. Mean age in the license group was 47 years, versus 63 years in the license-VFL group and 64 years in the nolicense group (not shown in Table 1). The license group also contained the highest percentage of workers/students. The most frequent diagnosis in the license group was diabetes, while glaucoma and stroke were the most common diagnoses in the other groups. Combined and/ or other diagnosis was the most common diagnosis in the license-VFL group. The highest percentage of respondents with no car in the household was in the no-license group. In the no-license group, the average duration of having had one's license withdrawn was approximately four years, with a range of $0-26$ years (mean $=4.2$ years, $\mathrm{SD}=4.3$; not shown in the table).

\section{Results}

\subsection{Overall subjective well-being}

Table 2 presents the model estimation results regarding the two dimensions of overall SWB. To control for aspects such as differences in age and gender composition between the groups, a range of such control variables was included in the model. Regarding the $S W B$ dimension of life satisfaction, both license groups were rated higher on this SWB dimension than was the nolicense group, and there was also a statistically significant difference between the two license groups, with the license-VFL group rated higher $(Z=2.49, p=0.013$; not shown in Table 2). The mean value was $7.05(\mathrm{SD}=2.41)$ for the license group, $8.33(\mathrm{SD}=1.90)$ for the licenseVFL group, and $4.69(\mathrm{SD}=3.16)$ for the no-license group.

Regarding the $S W B$ dimension of affects, both license groups had a higher level of SWB than did the no-license group, whereas there was no difference between the two license groups $(Z=1.53, p=0.127$; not shown in Table 2$)$.
The mean value was $3.65(\mathrm{SD}=0.86)$ for the license group, $4.10(\mathrm{SD}=0.62)$ for the license-VFL group, and $3.54(\mathrm{SD}=0.84)$ for the no-license group.

To investigate the relationship between time of license withdrawal and SWB in the no-license group, Pearson correlation was calculated between the variable Years of driving license withdrawal and the two SWB dimensions. No significant relationship was found for either the $S W B$ dimension of life satisfaction or the SWB dimension of affects ( $r=0.06$ and 0.02 , respectively).

\subsection{Frequency of trips for participation in different activities}

Access to activities measured by frequency of actual trips is presented in Table 3. To identify any differences across the three groups, non-parametric Kruskal-Wallis tests were used. Differences were identified across the three respondent groups regarding frequency of trips to work/studies, leisure activities, and friends/relatives, but not to care centre/hospital/pharmacy and shopping/other errands (however, $p=0.051$ for the last two). To determine which groups differed from one another, pairwise Mann-Whitney $U$ tests were used for the three described activities. The tests were adjusted using Bonferroni correction. As three comparisons were made for each activity, the $p$ values had to be below $0.016(0.05 / 3)$ to be significant at the $5 \%$ level. The license group and the license-VFL group made more trips to work/stud$i e s$ than did the no-license group $(Z=-4.95, p<0.001$ and $Z=-2.78, p<0.01$, respectively). A statistically significant difference was found between the license and license-VFL groups $(Z=-2.05, p<0.05)$, with the license group making more trips. Regarding trips for leisure activities, the license-VFL group made more trips than did the two others (license group $Z=-2.95, p<0.01$; nolicense group $Z=-4.72, p<0.001$ ), whereas no difference was evident between the license and no-license groups $(Z=-1.52, p=0.139)$. The license-VFL group made trips to friends/relatives more frequently (license group $Z=-2.82, p<0.01$; no-license group $Z=-3.44, p<0.01$ ) and there was no difference between the two other groups. The license group made no more such trips than did the no-license group $(Z=-0.44, p=0.886)$.

\subsection{Use of transport means to access different activities}

Use of transport means to access different activities was measured by asking how often out of ten times the respondent used (or would have used, for activities performed less often, i.e., visiting care centre/hospital/pharmacy) a given transport means to access a given activity, transformed to frequency. In addition, the respondents were asked whether they had any impairment other than VFL that might affect their opportunities to use any of the 
Table 2 Regression estimates regarding the two dimensions of SWB

\begin{tabular}{|c|c|c|c|c|}
\hline \multirow[t]{2}{*}{ Variable } & \multicolumn{2}{|c|}{ SWB dimension of life satisfaction } & \multicolumn{2}{|c|}{ SWB dimension of affects } \\
\hline & Coefficient & Robust S.E & Coefficient & Robust S.E \\
\hline \multicolumn{5}{|l|}{ Respondent group } \\
\hline License & $2.395^{* * *}$ & 0.427 & $0.338^{*}$ & 0.136 \\
\hline License-VFL & $3.500^{* * *}$ & 0.285 & $0.554^{* * *}$ & 0.082 \\
\hline No-license & Reference & & Reference & \\
\hline \multicolumn{5}{|l|}{ Gender } \\
\hline Male & -0.352 & 0.316 & 0.167 & 0.093 \\
\hline Female & Reference & & Reference & \\
\hline \multicolumn{5}{|l|}{ Age } \\
\hline 20-49 years & 0.193 & 0.372 & -0.080 & 0.113 \\
\hline $50-69$ years & Reference & & Reference & \\
\hline 70-95 years & $0.867^{*}$ & 0.369 & $0.317^{* *}$ & 0.099 \\
\hline \multicolumn{5}{|l|}{ Residence } \\
\hline City $>50,000$ & 0.640 & 0.406 & $0.264^{*}$ & 0.114 \\
\hline City $10,000-50,000$ & $0.864^{*}$ & 0.413 & $0.300^{* *}$ & 0.111 \\
\hline Town 200-9999 & 0.526 & 0.469 & 0.210 & 0.132 \\
\hline Countryside/rural & Reference & & Reference & \\
\hline \multicolumn{5}{|l|}{ Employment } \\
\hline Worker/student & 0.442 & 0.347 & 0.089 & 0.098 \\
\hline Unemployment/long-term sick/retired/other & Reference & & Reference & \\
\hline \multicolumn{5}{|l|}{ Highest education } \\
\hline Lower secondary school (age 7-15) & -0.908 & 0.583 & -0.209 & 0.138 \\
\hline Upper-secondary school (age 16-18) & $-1.220^{* * *}$ & 0.323 & -0.124 & 0.090 \\
\hline Further education (other than university) & $-1.297^{* * *}$ & 0.346 & $-0.273^{* *}$ & 0.099 \\
\hline Higher education (e.g., university) & Reference & & Reference & \\
\hline \multicolumn{5}{|l|}{ Family situation } \\
\hline Single with children & -0.679 & 0.667 & -0.066 & 0.160 \\
\hline Single without children & $-1.078^{* *}$ & 0.397 & $-0.351^{* *}$ & 0.107 \\
\hline Cohabiting with children & -0.366 & 0.315 & -0.075 & 0.094 \\
\hline Cohabiting without children & Reference & & Reference & \\
\hline \multicolumn{5}{|l|}{ Accommodation } \\
\hline Apartment & -0.201 & 0.343 & -0.131 & 0.102 \\
\hline Detached or terraced house/other & Reference & & Reference & \\
\hline \multicolumn{5}{|l|}{ Diagnosis } \\
\hline Stroke (only) & -0.375 & 0.352 & -0.150 & 0.091 \\
\hline Diabetes (only) & -0.874 & 0.468 & $-0.331^{*}$ & 0.129 \\
\hline Glaucoma (only) & Reference & & Reference & \\
\hline Combined and/or other diagnosis & -0.944 & 0.483 & $-0.528^{* * *}$ & 0.142 \\
\hline Constant & $5.528^{* * *}$ & 0.495 & $3.493^{* * *}$ & 0.137 \\
\hline$R^{2}$ & 0.329 & & 0.226 & \\
\hline N & 436 & & 436 & \\
\hline
\end{tabular}

All independent variables are dummy variables. The Number of cars in household variable is excluded from the analysis, as this aspect is covered by variables such as License and Family situation

S.E. $=$ Standard error

${ }^{*} p<.05 ; * * 0<.01 ; * * * 0.001$ 


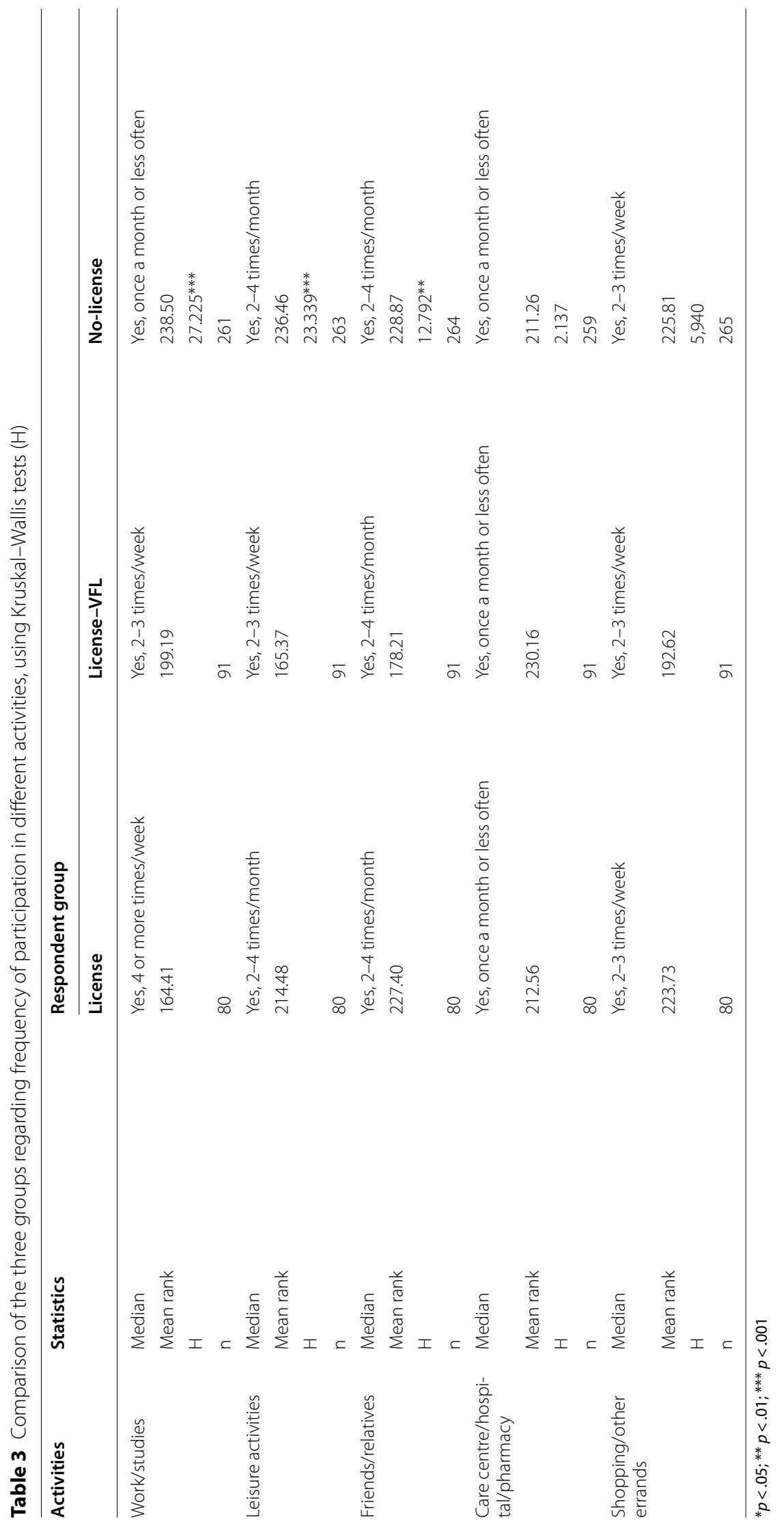


described transport means. Very few replied that this was the case, so this question was not investigated further.

In the two groups with driving licenses, regardless of activity, the car was most frequently used. In the nolicense group, it was generally most common to get a lift in a car to access the different activities; the exception was work/study trips, for which getting a lift in a car and public transport were used to the same extent (however, these trips were rare) (Fig. 1).

\subsection{Perceived access to transport means in order to live a life to be satisfied with}

In Table 4, the three license groups are compared regarding Perceived access to transport means in order to live a

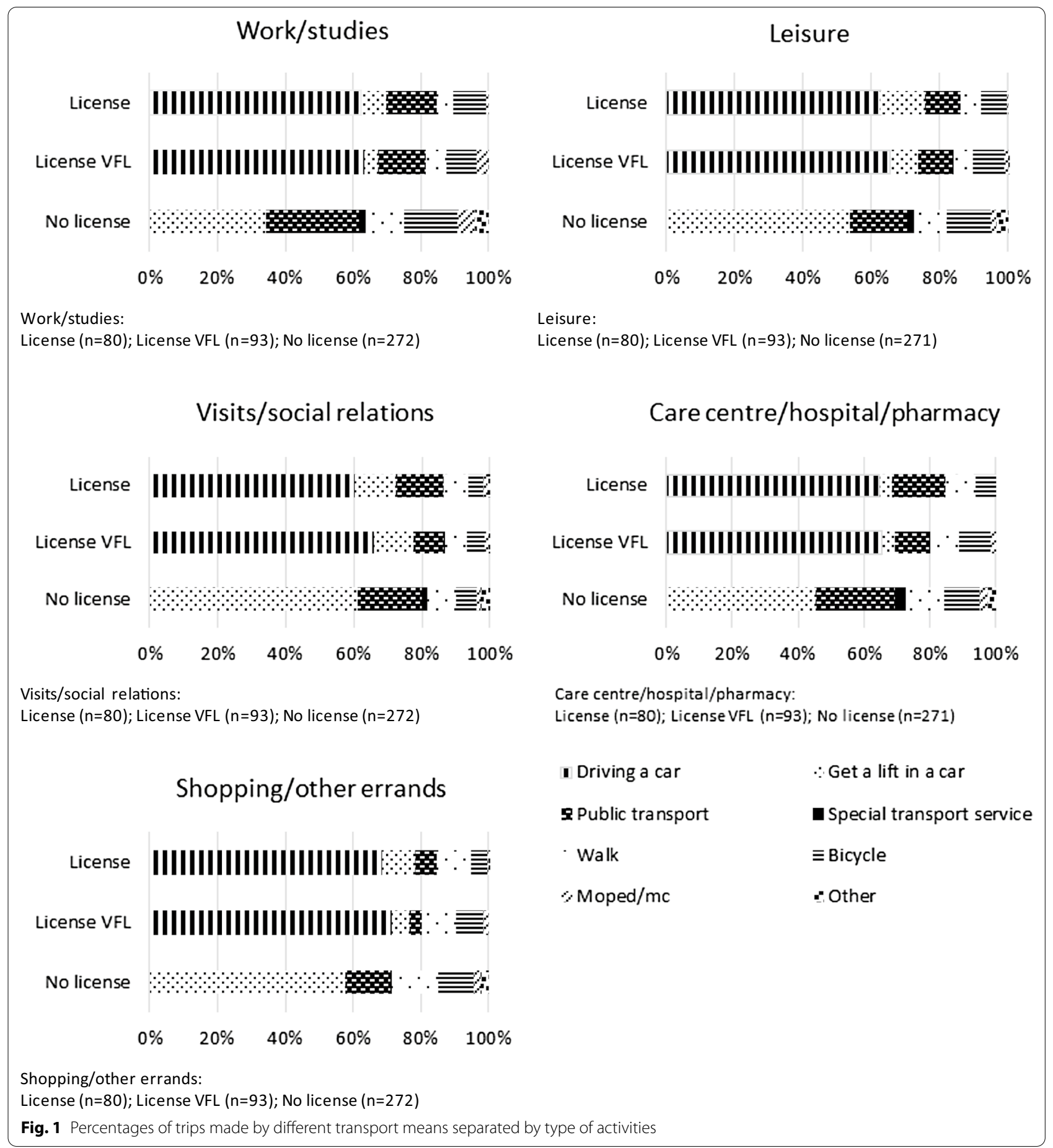


Table 4 Regression estimates regarding Perceived access to transport means in order to live a life to be satisfied with

\begin{tabular}{|c|c|c|}
\hline Variable & Coefficient & Robust S.E \\
\hline \multicolumn{3}{|l|}{ Respondent group } \\
\hline License & $6.824^{* * *}$ & 0.289 \\
\hline License-VFL & $6.407^{* * *}$ & 0.294 \\
\hline No-license & Reference & \\
\hline \multicolumn{3}{|l|}{ Gender } \\
\hline Male & 0.218 & 0.306 \\
\hline Female & Reference & \\
\hline \multicolumn{3}{|l|}{ Age } \\
\hline $20-49$ years & 0.336 & 0.319 \\
\hline $50-69$ years & Reference & \\
\hline 70-95 years & 0.234 & 0.341 \\
\hline \multicolumn{3}{|l|}{ Residence } \\
\hline City $>50,000$ & $1.077^{* *}$ & 0.351 \\
\hline City $10,000-50,000$ & $1.027^{* *}$ & 0.335 \\
\hline Town 200-9999 & 0.463 & 0.471 \\
\hline Countryside/rural & Reference & \\
\hline \multicolumn{3}{|l|}{ Employment } \\
\hline Worker/student & 0.098 & 0.288 \\
\hline Unemployment/long-term sick/retired/other & Reference & \\
\hline \multicolumn{3}{|l|}{ Highest education } \\
\hline Lower secondary school (age 7-15) & -0.627 & 0.502 \\
\hline Upper-secondary school (age 16-18) & $-0.803^{* *}$ & 0.297 \\
\hline Further education (other than university) & -0.511 & 0.317 \\
\hline Higher education (e.g., university) & Reference & \\
\hline \multicolumn{3}{|l|}{ Family situation } \\
\hline Single with children & $-.1 .320^{*}$ & 0.543 \\
\hline Single without children & $-0.796^{*}$ & 0.330 \\
\hline Cohabiting with children & -0.110 & 0.287 \\
\hline Cohabiting without children & Reference & \\
\hline \multicolumn{3}{|l|}{ Accommodation } \\
\hline Apartment & $0.564^{*}$ & 0.287 \\
\hline Detached or terraced house/other & Reference & \\
\hline \multicolumn{3}{|l|}{ Diagnosis } \\
\hline Stroke (only) & -0.528 & 0.307 \\
\hline Diabetes (only) & $-0.904^{*}$ & 0.365 \\
\hline Glaucoma (only) & Reference & \\
\hline Combined and/or other diagnosis & $-0.891^{*}$ & 0.430 \\
\hline Constant & $2.491^{* * *}$ & 0.483 \\
\hline$R^{2}$ & 0.675 & \\
\hline$N$ & 436 & \\
\hline
\end{tabular}

All independent variables are dummy variables. The Number of cars in household variable is excluded from the analysis, as this aspect is covered by othervariables such as License and Family situation

S.E. $=$ Standard error

${ }^{*} p<.05$; ${ }^{* *} p<.01$; ${ }^{* * *} p<.001$

life to be satisfied with. The table shows that both license groups were more satisfied than was the no-license group $(p<0.001)$, but with no difference between the two groups with a driving license $(Z=-1.43, p=0.152)$. The mean value was $9.41(\mathrm{SD}=1.19)$ for the license group,
$9.09(\mathrm{SD}=2.30)$ for the license-VFL group, and 2.60 $(\mathrm{SD}=2.81)$ for the no-license group.

Table 5 presents results regarding Desire for greater use of a transport means to live a satisfying life. In the 
no-license group, the most desired transport means was car driving (96\%). Getting more lifts by car was not desired at all in the license-VFL group and was desired only slightly in the two other groups. The strongest desire for greater use of public transport and for bicycle was observed in the license group (16.5\% and $11.5 \%$, respectively).

\section{Discussion}

The purpose of this study was to investigate whether and how driving license withdrawal due to VFL affects SWB. The assumption is that access to transport facilitates the accessibility of activities that generate SWB. The focus was on differences in SWB between a group of people whose driving license was withdrawn due to VFL and groups with a driving license.

\subsection{Overview of findings}

Even when controlling for age, diagnosis, and other potential confounding variables, the two license groups had higher overall SWB than did the no-license group. The nolicense group was also much more unsatisfied than were those with a driving license, regarding Perceived access to transport means in order to live a life to be satisfied with. Furthermore, the no-license group had a very strong desire to drive a car (96\%), while the two other groups did not express a desire for greater use of any specific transport means in order to live a satisfying life. This is in line with previous findings that license withdrawal can lead to worsened SWB $[5,7,14,24,37]$ and that car users are more satisfied with their transport means than are people using other transport means [9]. Altogether, according to the results of this study, having a driving license withdrawn due to VFL does affect SWB. Also, it should be noted that very few respondents stated that they had any impairment other than VFL that might affect their opportunities to use any of the described transport means (i.e., drive a car, get a lift in a car, use public transport, use the special transport service, walk, bicycle, and drive a moped/ motorcycle). However, we cannot ignore the possibility that factors other than those controlled for might affect SWB. Regarding trips to work/studies, self-reported trip frequencies were highest in the license group, followed by the license-VFL group, with the no-license group reporting a very low trip frequency. This is partially aligned with the employment rate of each group. The license-VFL group made more trips for leisure activities and to see friends and relatives than did the two other groups. This can be understood given that most respondents in the license group were employed and might not have as much time for leisure activities and trips to see friends and relatives (cf. [3]. The license-VFL group was also rated higher than the other two groups on the SWB dimension of life satisfaction, which hints at something to investigate in further research. Regarding the no-license group, insufficient alternative transport means could explain fewer trips for leisure activities and to see friends and relatives compared with the license-VFL group. For trips to the care centre/ hospital/pharmacy and for shopping and errands, no differences could be detected between the groups.

Altogether, these results show differences between the groups regarding frequency of trips to certain activities; however, when these differences are observed, they cannot be explained solely by having or not having a driving license. This implies that qualitative aspects other than the relationship between the frequencies of trips and activities, but that were not fully captured here, may be of greater importance in understanding transport-related SWB. Furthermore, as stated by Delbosc [8], measuring well-being by frequency of trips is a blunt indicator, "as it does not take into consideration how much travel a person desires to make." (p. 31). Moreover, the link between SWB and trip frequency may depend on many context variables, such as trip purpose and spatial effects [6]. The lack of information about such variables in this study is somewhat compensated for by the variables Perceived access to transport

Table 5 Percentages of those desiring to use specific transport means to a greater extent

\begin{tabular}{|c|c|c|c|c|c|c|}
\hline \multirow[t]{2}{*}{ Transport means } & \multicolumn{2}{|c|}{ License } & \multicolumn{2}{|c|}{ License-VFL } & \multicolumn{2}{|c|}{ No-license } \\
\hline & $\%$ & $n$ & $\%$ & $n$ & $\%$ & $n$ \\
\hline Car driving & 14.1 & 11 & 12.1 & 11 & 95.8 & 254 \\
\hline Getting a lift in a car & 2.6 & 2 & 0 & 0 & 9.2 & 24 \\
\hline Public transport & 16.5 & 13 & 8.8 & 8 & 6.9 & 18 \\
\hline Special transport service & 0 & 0 & 0 & 0 & 4.6 & 12 \\
\hline Bicycle & 11.5 & 9 & 3.3 & 3 & 4.2 & 11 \\
\hline Walking & 7.7 & 6 & 4.4 & 4 & 1.9 & 5 \\
\hline Moped/mc & 1.3 & 1 & 1.1 & 1 & 0 & 0 \\
\hline
\end{tabular}

The respondents could choose several transport means or even refrain from choosing at all, so the percentages will not sum to 100 
means in order to live a life to be satisfied with and Desire for greater use of a transport means to live a satisfying life. Thus, getting a lift as the dominant means of transportation in the no-license group may give rise to qualitative aspects such as negative experiences of interpersonal dependency and restricted self-determination. Also, previous studies have revealed that dependence on others to get a lift in a car can lead to worsened SWB $[4,24]$.

This study contributes new knowledge to previous research on SWB related to driving license withdrawal, as it has a wider perspective than the often-investigated research group of the elderly. Considering that license withdrawal can affect a person's life in such a negative manner, the results could apply to groups with impairments other than VFL (e.g., neuropsychiatric diagnoses, epilepsy, or motor difficulties after a stroke) who likewise do not meet the medical requirements for driving licenses. Such knowledge constitutes an important factor to consider when, for example, formulating regulations and policies related to obstacles and opportunities that individuals with impairments face when using the transport system (cf. [25]). Still, this subject merits more research, as qualitative aspects other than the relationship between the frequencies of trips and activities might also affect SWB.

Finally, as diagnoses such as glaucoma, diabetes, and stroke above all are age related, they are projected as likely to increase in the future due to population ageing $[21,26$, 33]. Hence, driving license withdrawal due to VFL might increase, which might also have an impact on SWB, highlighting the importance of studies such as this one.

\subsection{Methodological considerations}

As the study was based on a convenience sample, it could be questioned whether the results can be generalized. However, the surveys were distributed via the websites of three large disability organizations in Sweden (i.e., the diabetes, glaucoma, and stroke organizations), giving individuals of various sociodemographic backgrounds the opportunity to take part in the study, apart from their diagnoses. Regarding the no-license group, there is also the risk that the propensity to participate, as well as how the questions were answered, might depend on the respondents' perceptions of having been unfairly treated concerning the license withdrawal. This potential bias is difficult to avoid but is important to keep in mind.

In this study, we made the assumption that access to transport facilitates the accessibility of activities that generate SWB. These relationships were not tested directly, which may be a limitation of the study. We therefore propose further research with purpose to estimate models for the relationships between access to transport, accessibility of activities, and SWB.

The questions about overall SWB constituted the last part of the questionnaires, and respondents' answers to previous questions might have affected their later answers regarding overall SWB (cf. [16]. As the respondents were aware that the study concerned how driving license withdrawal might affect SWB, the order of questions should not have had a major impact.

In total, 438 of the 581 people who registered for the web survey were included in the study. Two kinds of dropouts were seen: the first were people who, for unknown reasons, answered only the background questions, or parts of them, whereas the second were people who discontinued the questionnaire at the halfway point, and thus were excluded. One possible explanation for these dropouts is that the questions were asked in a way perceived as too complicated to answer.

\section{Conclusions}

In this study, it was shown that people who had their driving license withdrawn due to VFL (i.e., the licenseVFL group) had lower SWB than did people with a driving license (i.e., the license group). Respondents whose driving license was withdrawn also perceived that they had less access to transport means in order to live a life to be satisfied with than did those with a driving license. They also had a strong desire to drive a car, while those with a driving license did not express a desire for greater use of any specific transport means in order to live a satisfying life. Altogether, this indicates that driving license withdrawal does affect SWB. Furthermore, the licenseVFL group made more trips for leisure activities and to see friends and relatives than did the two other groups, possibly because lower employment in this group than the license group made more time available for such activities. However, low employment also characterized the no-license group. For this group, explanations other than time availability could explain fewer trips for leisure activities and to see friends and relatives, such as insufficient alternative transport means.

As the results might also apply to other groups with impairments other than VFL, they contribute to our understanding of the elderly who no longer have a driving license. Such knowledge is important considering regulations and policies regarding transportation and people with impairments. However, the results imply that qualitative aspects other than the relationship between the frequencies of trips and activities might also affect SWB, aspects such as negative experiences of interpersonal dependency and restricted self-determination, although more research on this subject is needed. 


\section{Acknowledgements}

The authors would like to acknowledge the Swedish Diabetes Association, Swedish Glaucoma Association, and Swedish Stroke Association for their help in recruiting respondents. We also acknowledge Per Henriksson of VTI who provided initial statistical support. Thanks also to Birgitta Thorslund of VTI for her wise comments and advice on this paper.

\section{Authors' contributions}

JN, $\AA A, H-Y$ B and TS contributed to the study conception and design. GB designed and performed the analysis. JN wrote the paper, though with contributions from the other authors. All the authors approved the final manuscript.

\section{Funding}

Open access funding provided by Örebro University. The study was supported by the Swedish Transport Agency.

\section{Availability of data and materials}

The datasets used and analysed during the current study are available from the corresponding author on reasonable request.

\section{Competing interests}

The authors declare that they have no competing interests.

\section{Author details}

${ }^{1}$ Swedish National Road and Transport Research Institute, Linköping, Sweden.

${ }^{2}$ School of Law, Psychology and Social Work, Örebro University, Örebro, Sweden. ${ }^{3}$ The Swedish Institute for Disability Research, Örebro University, Örebro, Sweden. ${ }^{4}$ Department of Global Public Health, Karolinska Institutet, Stockholm, Sweden. ${ }^{5}$ Swedish Transport Agency, Borlänge, Sweden. ${ }^{6}$ School of Health and Welfare, Dalarna University, Falun, Sweden.

Received: 7 October 2020 Accepted: 30 August 2021

Published online: 15 September 2021

\section{References}

1. Adler, G., \& Rottunda, S. (2006). Older adults' perspectives on driving cessation. Journal of Aging Studies, 20, 227-235.

2. Bantis, T., \& Haworth, J. (2020). Assessing transport related social exclusion using a capabilities approach to accessibility framework: A dynamic Bayesian network approach. Journal of Transport Geography, 84, 102673.

3. Berg, J. (2016). Everyday mobility and travel activities during the first years of retirement. (Doctoral dissertation). Linköping University, Department of Social and Welfare Studies.

4. Burkhardt, J. E. (1999). Mobility changes: Their nature, effects, and meaning for elders who reduce or cease driving. Transportation Research Record, 1671(1), 11-18.

5. Chihuri, S., Mielenz, T. J., Dimaggio, C. J., Betz, M. E., Diguiseppi, C., Jones, V. C., \& Li, G. (2016). Driving cessation and health outcomes in older adults. Journal of the American Geriatrics Society, 64(2), 332-341.

6. Cordera, R., Coppola, P., dell'Olio, L., \& Ibeas, A. (2017). Is accessibility relevant in trip generation? Modelling the interaction between trip generation and accessibility taking into account spatial effects. Transportation, 44(6), 1577-1603.

7. Davey, J. A. (2007). Older people and transport: Coping without a car. Ageing and Society, 27(01), 49-65.

8. Delbosc, A. (2012). The role of well-being in transport policy. Transport Policy, 23, 25-33.

9. De Vos, J. (2018). Do people travel with their preferred travel mode? Analysing the extent of travel mode dissonance and its effect on travel satisfaction. Transportation Research Part A: Policy and Practice, 117, 261-274.

10. De Vos, J., Schwanen, T., Van Acker, V., \& Witlox, F. (2013). Travel and subjective well-being: A focus on findings, methods and future research needs. Transport Reviews, 33(4), 421-442.

11. Dodson, J., Gleeson, B., \& Sipe, N. (2004). Transport disadvantage and social status: A review of literature and methods (Urban Policy Program Research Monograph 5). Griffith University.

12. Eurostat (2015). Quality of life: Facts and views. Luxembourg: Publications Office of the European Union.
13. Geurs, K. T., \& van Wee, B. (2004). Accessibility evaluation of land-use and transport strategies: Review and research directions. Journal of Transport Geography, 12(2), 127-140.

14. Harrison, A., \& Ragland, D. R. (2003). Consequences of driving reduction or cessation for older adults. Transportation Research Record, 1843(1), 96-104.

15. International Diabetes Federation (IDF) (2021). About diabetes. Retrieved March 23, 2021, from https://www.idf.org/aboutdiabetes/what-is-diabe tes/facts-figures.html.

16. Makarewicz, C., \& Németh, J. (2018). Are multimodal travelers more satisfied with their lives? A study of accessibility and wellbeing in the Denver, Colorado metropolitan area. Cities, 74, 179-187.

17. Martens, K. (2017). Transport justice: Designing fair transportation systems. Routledge.

18. Mattioli, G. (2014). Where sustainable transport and social exclusion meet: Households without cars and car dependence in Great Britain. Journal of Environmental Policy \& Planning, 16(3), 379-400.

19. Mokhtarian, P. L. (2019). Subjective well-being and travel: Retrospect and prospect. Transportation, 46(2), 493-513.

20. Musselwhite, C., \& Haddad, H. (2010). Mobility, accessibility and quality of later life. Quality in Ageing and Older Adults (QAOA), 11(1), 25-37.

21. NCD Risk Factor Collaboration (NCD-RisC) (2016). Worldwide trends in diabetes since 1980: A pooled analysis of 751 population-based studies with 4.4 million participants. The Lancet, 387(10027), 1513-1530.

22. Nordbakke, S., \& Schwanen, T. (2014). Well-being and mobility: A theoretical framework and literature review focusing on older people. Mobilities, 9(1), 104-129.

23. Novavision (2021). 9 facts about stroke and loss of vision Retrieved March 23, 2021, from https://novavision. com/9-facts-about-stroke-and-loss-of-vision/.

24. Nyberg, J., Strandberg, T., Berg, H. Y., \& Aretun, Å. (2019). Welfare consequences for individuals whose driving licenses are withdrawn due to visual field loss: A Swedish example. Journal of Transport \& Health, 14, 100591.

25. OECD. (2013). OECD Guidelines on Measuring Subjective Well-being. OECD Publishing.

26. Ogurtsova, K., da Rocha Fernandes, J. D., Huang, Y., Linnenkamp, U., Guariguata, L., Cho, N. H., Cavana, D., Shaw, J. E., \& Makaroff, L. E. (2017). IDF diabetes Atlas: Global estimates for the prevalence of diabetes for 2015 and 2040. Diabetes Research and Clinical Practice, 128, 40-50.

27. Patterson, G., Howard, C., Hepworth, L., \& Rowe, F. (2019). The impact of visual field loss on driving skills: A systematic narrative review. British and Irish Orthoptic Journal, 15, 53-63.

28. Pereira, R. H., Schwanen, T., \& Banister, D. (2017). Distributive justice and equity in transportation. Transport Reviews, 37(2), 170-191.

29. Porter, A. (2002). Compromise \& constraint: Examining the nature of transport disability in the context of local travel. World Transport Policy and Practice, 8(2), 9-16.

30. Reardon, L., \& Abdallah, S. (2013). Well-being and transport: Taking stock and looking forward. Transport Reviews, 33(6), 634-657.

31. SCB (2018). ULF/SILC 2018 Frågeformulär ULF/SILC (tvärsnitt) [ULF/SILC 2018 questionnaire ULF/SILC (cross section)]. Stockholm: Statistiska centralbyrån.

32. Stanley, J. K., Hensher, D., Stanley, J. R., \& Vella-Broderick, D. (2011). Mobility, social exclusion and well-being: Exploring the links. Transportation Research Part A, 45, 789-801.

33. Tham, Y., Li, X., Wong, T. Y., Quigley, H. A., Aung, T., \& Cheng, C. (2014). Global prevalence of glaucoma and projections of glaucoma burden through 2040: A systematic review and meta-analysis. Ophthalmology, 121, 2081-2090.

34. Transportstyrelsen (2018). Körkortsåterkallelserna ökar i antal [Withdrawals are increasing in number]. Retrieved September 29, 2018, from https:// www.transportstyrelsen.se/sv/Press/Pressmeddelanden/2018/korkortsat erkallelserna-okar-i-antal/

35. Turner, M., Liddle, J., \& Pachana, N. A. (2016). Parkinson's disease and driving cessation: A journey influenced by anxiety. Clinical Gerontologist, 40(3), 220-229

36. Van Wee, B. (2016). Accessible accessibility research challenges. Journal of Transport Geography, 51, 9-16.

37. Whitehead, B. J., Howie, L., \& Lovell, R. K. (2006). Older people's experience of driver licence cancellation: A phenomenological study. Australian Occupational Therapy Journal, 53(3), 173-180. 
38. World Health Organization (WHO) (2021). Eye care, vision care, vision impairment and blindness. Retrieved March 23, 2021, from https://www. who.int/health-topics/blindness-and-vision-loss\#tab=tab_1.

39. Zeitler, E., \& Buys, L. (2015). Mobility and out-of-home activities of older people living in suburban environments: "Because I'm a driver, I don't have a problem." Ageing and Society, 35(04), 785-808.

\section{Publisher's Note}

Springer Nature remains neutral with regard to jurisdictional claims in published maps and institutional affiliations.

\section{Submit your manuscript to a SpringerOpen ${ }^{\circ}$ journal and benefit from:}

- Convenient online submission

- Rigorous peer review

- Open access: articles freely available online

- High visibility within the field

- Retaining the copyright to your article

Submit your next manuscript at springeropen.com 